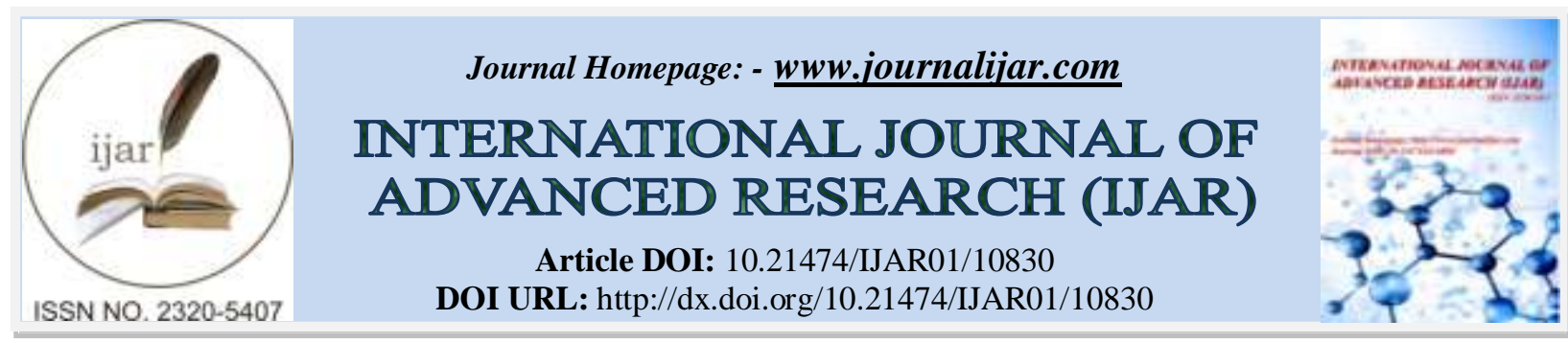

RESEARCH ARTICLE

\title{
CLINICAL IMPLICATIONS OF MULLERIAN ANOMALIES: A CASE SERIES
}

\author{
Aastha Garg ${ }^{1}$, Rupinder Singla ${ }^{2}$ and Mini Bedi ${ }^{3}$ \\ 1. Senior Resident, Department of Gynecology and Obstetrics, GMC Amritsar. \\ 2. Senior Resident, Department of Surgery, GMC Amritsar. \\ 3. Assistant Professor, Department of Gynecology and Obstetrics, AIMSR.
}

\section{Manuscript Info}

.a.n....................

Manuscript History

Received: 14 February 2020

Final Accepted: 16 March 2020

Published: April 2020

Key words:-

Unicornuate, Bicornuate, Mullerian Anomalies, Vaginal Septum, Renal Abnormality

\section{Abstract}

Mullerian developmental defects are congenital anomalies of the female reproductive tract which may adversely affect a woman's obstetric and gynaecologicalhealth.In the present study, all patients presenting with Mullerian anomalies in the department of Obstetrics\&Gynaecology were included. They were studied \& results were analysed including the incidence \& presenting complaints. They were classified into several groups using the AFS classification of Mullerian Anomalies,evaluated properly and treated accordingly. It was concluded that with proper evaluation, diagnostic workup and judicious management options these patients could lead a healthy life thereafter. Treatment is multidisciplinary and involves surgical and nonsurgical treatment options including the creation of a neovagina to have a normal sex life.

Copy Right, IJAR, 2020,. All rights reserved.

\section{Introduction:-}

Mayer RokintanskyKustner Hauser syndrome has a long history, which explains its long name. Mayer in 1829 first described congenital absence of the vagina as one of the features of stillborn fetuses with multiple congenital anomalies ${ }^{1}$. Rokintansky in 1838 and Kustner in 1910 described a syndrome wherein the vagina is absent with a rudimentary uterus, with normal ovaries and renal and skeletal anatomic defects ${ }^{2,3}$ Other names for this entity are Congenital Absence of the Uterus and Vagina (CAUV), Mullerian Aplasia (MA), or Genital Renal Ear Syndrome(GRES) ${ }^{4}$. The incidence is estimated at 1 in 4000-5000 female births. Even if this is rare, it is the second most common cause of primary amenorrhea, next only to gonadal dysgenesis. The etiology is still unknown, and it is not clear whether it is from genetic or environmental causes ${ }^{5,6}$. The syndrome has two types: type 1 or isolated or Rokintansky sequence, type 2 or the MURCS association (Mullerian duct aplasia, Renal dysplasia and Cervical Somite anomalies?

While MRKH Syndrome physical examination reveals normal height, body hair distribution, secondary sexual characteristics, and external genitalia, the patient will often have an absent vagina or shortened blind pouch without a cervix. Careful evaluation of abdominal, urinary tract, and skeletal structures is recommended as up to $53 \%$ of MRKH syndrome patients will have congenital malformations ${ }^{8}$

\section{Case Reports:}

A 22-year-old unmarried female presented with chief complaint of menarche not attained. Her height- $162 \mathrm{~cm}$, Arm span- $174 \mathrm{~cm}$ and had no previous medical or surgical illnesses. On examination-Axilllary hair absent, short neck, 
widely spaced nipple and breast not developed. On abdominal examination-soft, non tender, non distended. On local examination-sparse pubic hair. External genitalia apparently normal. On separating labia hymen seen. Introitus was normal. On per rectal examination-no mass felt.USG revealed small pear shape like structure likely rudimentary uterus, no well form uterus identified. no free fluid seen.

An 16-year-old unmarried female presented with chief complaint of menarche not attained, no spotting. Her height was $153 \mathrm{~cm}$, Arm span-161 cm, Thin built and had no previous medical or surgical illnesses. On examination Axillary hair-absent, bilateral breast mound-present, nipple and areola not developed. On abdominal examinationsoft, non tender, non distended. On local examination- pubic hair present. External genitalia apparently normal. On separating labia hymen seen. Introitus was normal. On per rectal examination-no mass felt.

USG revealed uterus-anteverted,normal size,ET-3mm,cervix normal,ovaries-normal,no adenexal mass, no free fluid. BARR bodies in PBF $>10 \%$ Drumstick, Buccal mucosa smear $<5 \%$.

A 17-year-old unmarried female presented with chief complaint of menarche not attained. Her height-145cm, Arm span-149cm and had no previous medical or surgical illnesses. On examination-Axillary hair sparse, short neck, widely spaced nipple and breast small mound present. On abdominal examination-soft, non tender, non distended. On local examination- pubic hair present. External genitalia apparently normal. On separating labia hymen seen. Introitus was normal. On per rectal examination-no mass felt.

USG revealed uterus not visible. Left ovary not seen. Right ovary normal. Impression-absent uterus.

A 18-year-old unmarried female presented with chief complaint of menarche not attained. Her height-168cm, Arm span-177cm and had no previous medical or surgical illnesses. On examination Axilllary hair sparse, short neck, widely spaced nipple and breast small mound present, areola not well developed, bilateral nipples retracted. On abdominal examination-soft, non tender, non distended. On local examination- pubic hair sparse. External genitalia apparently normal. Introitus was normal. On per rectal examination-no mass felt.

USG revealed uterus and ovaries not seen likely hypoplastic/agenesis of uterus and ovaries.

A 13-year-old un married female presented with chief complaint of pain lower abdomen associated with ammenorrhoea. Her height $-152 \mathrm{~cm}$, Arm span-161 cm and had no previous medical or surgical illnesses. Her IQ was normal and had difficulty in speaking from birth. On examination Depressed nose, difficulty in speaking, Low set ears, High arched palate, long fingers, increased carrying angles, Axilllary hair were sparse, small breast mound present . On abdominal examination-soft, non tender, non distended. On local examination- pubic hair present. External genitalia apparently normal. no outlet seen, no opening seen on separating labia.

MRI revealed possibly right unicornuate uterus with left rudimentary horn(class 2 mullerian duct anomaly) Hematometra?due to cervical stenosis and USG suggestive of hematocolpos and hematometra.

A 22-year-old married female presented with chief complaint of Abdominal pain every month not associated with bleeding. She had a history of menarche at 18 years only spotting for 2-3 days associated with decreased flow and dysmennorhoea. Her height-149cm, Arm span-144.6cm and had no previous medical or surgical illnesses. On examination-secondary sexual characters were well developed, bilateral breast soft non-tender. On abdominal examination-soft, non tender, non distended. On local examination- pubic hair present. On per vaginal examinationblind lower one-third of vagina. Uterus not felt. External genitalia apparently normal. Introitus was normal. On per rectal examination-no mass felt.

USG revealed uterus AV,hypoplastic $(2.3 \times 1.0 \mathrm{~cm})$ ET-2.2mm both ovaries hypoplastic. Left ovary-1.7x1.0 $\mathrm{cm}$ and right ovary- $1.5 \times 0.9 \mathrm{~cm}$. Significant free fluid seen in POD. No adenexal mass seen.

A 23-year-old married female presented with chief complaint of absence of menturation since 1.5 years. She had a history of menarche at 16 years only spotting every yearly for 1-2 days associated with decreased flow and dysmennorhoea. Her height-149cm, Arm span-144.6cm and had no previous medical or surgical illnesses. On examination- axillary hair-sparse, secondary sexual characters were well developed, bilateral breast soft non-tender. On abdominal examination-soft, non tender, non distended. On local examination- pubic hair sparse. On per vaginal examination-blind lower one-third of vagina. Uterus not felt, no cervix seen. External genitalia apparently normal. Introitus was normal. On per rectal examination-no mass felt. 
USG revealed MULLERIAN DUCT ANOMALY CLASS-1. Uterus hypoplastic/agenesis.both ovaries normal. no free fluid seen.

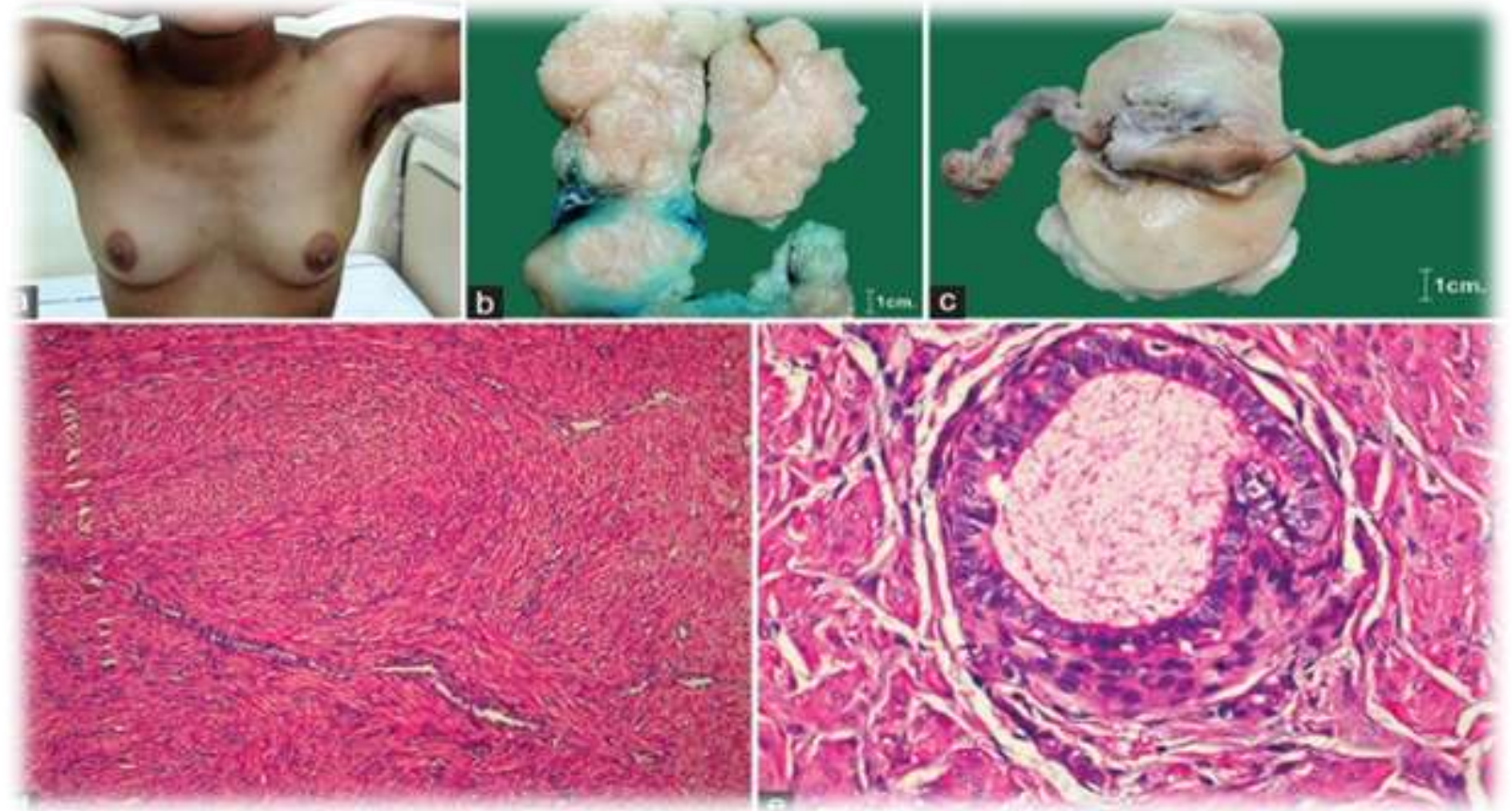

Figure: (a) Clinical photograph showing axillary hairs and normal breast development. (b) Gross photograph showing multiple leiomyomas in a hypoplastic uterus. (c) Rudimentary uterine horn with bilateral fallopian tubes. (d) Microphotograph showing leiomyoma (H and E, $\times 100)$. (e) Microphotograph showing rudimentary mullerian lining surrounded by smooth muscle.

\section{Discussion:-}

These patients usually present for consultation around the time of puberty when menarche is expected to occur. The average age at diagnosis is from 10-18 years ${ }^{7}$ The primary amenorrhea is due to the congenital absence of the upper two thirds of the vagina, the cervix, uterus and fallopian tubes which are derivatives of theMullerian ducts ${ }^{8}$. It is postulated that an event occurring around the fifth week of gestation interferes with the normal development of the mullerian or paramesonephric ducts resulting in uterine and vaginal abnormalities. Mullerian duct development is also dependent on the Wolffian (mesonephric) duct and this may explain why there are associated renal abnormalities $^{6}$. Affected individuals are phenotypically female and have a normal female karyotype (46, XX). They also develop secondary sexual characteristics. Levels of estradiol and the gonadotropins are normal as well. It has been found out that the patterns of hormonal secretion by the ovaries are within normal limits even in the absence of the uterus ${ }^{8}$. There are various differential diagnoses for primary amenorrhea and these would be sorted out based on the clinical information and diagnostic evaluation. Imperforate hymen and transverse vaginal septum may present in the same way but these entities would have a normal uterus. Also, since there is still normal endometrium in these cases, they may present with monthly hypogastric pains coinciding with the onset of menstrual flow ${ }^{5}$. Evaluation of a patient with primary amenorrhea should include a vaginal exam, uterine assessment, serum $\beta$-human chorionic gonadotropin, follicle-stimulating hormone, luteinizing hormone, prolactin, and thyroid-stimulating hormone levels. Karyotype analysis should be considered when differentiating testicular feminization and Turner syndrome (45, XO) from Mayer-Rokitansky-Küster-Hauser (MRKH) Syndrome. Free and total testosterone, as well as dehydroepiandrosterone sulfate, should be considered if signs of hyperandrogenism, such as virilization or hirsuitism, are present. Estradiol levels can be obtained if signs of estradiol exposure (e.g. thelarche) are not present. Progesterone levels can be obtained, followed by a progesterone challenge test to confirm functional anatomy if a uterus is indeed present. Transvaginal ultrasound should be first choice in imaging to assess for müllerian anomalies. A magnetic resonance imaging of the abdomen and pelvis can then be used to further describe those findings seen on screening transvaginal ultrasound. Lastly, if ultrasound and MRI are not yielding, laparoscopy can be performed to assess for degree of MRKH anomalies ${ }^{5}$. 
Treatment is multidisciplinary and involves surgical and nonsurgical treatment options including the creation of a neovagina to have a normal sex life. Vestiges of uterus can be removed to avoid the development of endometriosis ${ }^{1}$. The timing of surgical or nonsurgical creation of the neovagina should be planned for when the woman is emotionally mature and expresses the desire for correction.

The nonsurgical creation of the neovagina requires patients to manually place successive dilators on the vaginal dimple for $30 \mathrm{~min}$ to $2 \mathrm{~h}$ /day. In highly motivated patients, a functional vagina will be created over several months. However, following successful dilation, intermittent dilation therapy will be required in those that are not sexually active ${ }^{9}$. Surgical creation of a neovagina is an option for patients who prefer the surgical correction or those who were unsuccessful with dilators. Surgical correction just like the nonsurgical options requires postoperative dilation or regular sexual intercourse to maintain adequate vaginal length and diameter ${ }^{8}$. Surgery aims to create a vaginal canal in the correct axis of adequate size and secretory capacity to allow intercourse. A procedure commonly done involves dissection of space between the rectum and the bladder, placement of a mold into the space covered with a split-thickness skin graft. After healing, serial dilation is done to prevent skin graft contracture. A neovagina can also be created laparoscopically. Other forms of grafts that can be used include buccal mucosa, bowel mucosa and amnion ${ }^{3}$.

\section{Conclusion:-}

MRKH syndrome is a rare anomaly of the Mullerian duct. Despite the clinical management options available, the distress of having such a condition is better managed with support from psychologists, counselors and a strong social and family support group

MRKH is a malformation complex comprising absent vagina and absent or rudimentary uterus. This is understandable given the incomplete degree of penetrance, variable expressivity, and similarities of this syndrome with other genetic disorders. Treatment which consists in creating a neovagina is generally offered to patients when they are ready to start sexual activity.

\section{Conflict of interest:}

All the authors declare that they have no conflict of interest and they have not received any grant.

\section{References:-}

1. Manfroi RG, Chagas LA, Leal R, Cunha AL, Djahjah MC. Mayer-Rokitansky-Kuster-Hauser syndrome: A case report and literature review. Radiol Bras 2011;44:192-4.

2. Sultan C, Biason-Lauber A, Philibert P. Mayer-Rokitansky-Kuster-Hauser syndrome: Recent clinical and genetic findings. GynecolEndocrinol 2009;25:8-11.

3. Parikh R, Nakum K, Kadikar G, Gokhle A. Mullerian anomalies: A cause of primary amenorrhea. Int J ReprodContraceptObstetGynecol 2013;2:393-7.

4. Evans TN, Poland ML, Boving RL. Vaginal malformations. Am J ObstetGynecol 1981;141:910-20.

5. Guerrier D, Mouchel T, Pasquier L, Pellerin I. The Mayer-Rokitansky-Kuster-Hauser syndrome (congenital ansence of uterus and vagina)-phenotypic manifestations and genetic approaches. J Negat Results Biomed 2006;5:1.

6. Strübbe EH, Willemsen WN, Lemmens JA, Thijn CJ, Rolland R. Mayer-Rokitansky-Küster-Hauser syndrome: Distinction between two forms based on excretory urographic, sonographic, and laparoscopic findings. AJR Am J Roentgenol 1993;160:331-4.

7. Mueller GC, Hussain HK, Smith YR, Quint EH, Carlos RC, Johnson TD, et al. Müllerian duct anomalies: Comparison of MRI diagnosis and clinical diagnosis. AJR Am J Roentgenol 2007;189:1294-302.

8. Yakasai A, Daneji SM, Natasha A, Yunus EM. Late presentation of mayer-rokitansky-kuster-hauser syndrome in the tropics-Northern Nigeria. Br J Med Res 2015;5:1077-82.

9. Committee on Adolescent Health Care. Mullerian agenesis: Diagnosis management and treatment. ACOG; 2013. p. 562. 